\title{
Recursos educativos digitais e o ensino/aprendizagem da gramática*
}

\author{
Adriana Cardoso*, Ricardo Pereira Rodrigues**, Liliana Freitas***, Dina Caetano \\ Alves**** \\ *Instituto Politécnico de Lisboa, Escola Superior de Educação \\ Universidade de Lisboa, Centro de Linguística \\ **Instituto Politécnico de Lisboa, Escola Superior de Comunicação Social \\ ***Instituto Politécnico de Lisboa, Escola Superior de Educação \\ Colégio do Tejo \\ ****Instituto Politécnico de Setúbal, Escola Superior de Saúde \\ Universidade de Lisboa, Centro de Linguística
}

\begin{abstract}
:
This paper presents two digital educational resources (DER), which aim at promoting the development of metalinguistic competence of students attending the 3rd grade of Primary School (age 8/9). The digital resource Laboratório Gramatical Digital: A Força das Sílabas [Digital Grammar Lab: The strength of syllables] promotes the development of metaphonological competence of students on the phonological word stress in European Portuguese. It adopts a discovery-learning approach through the implementation of a grammar laboratory ('Grammar Lab'). The digital resource Cozinhar a Aprender [Cooking to Learn] offers a learning experience where users build their own knowledge on a specific textual genre (recipe) through the analysis of concrete examples (or models) of this textual genre. The didactic approach implemented draws upon the notion of text genre and the model of didactic sequence. These two DER aim to contribute to a paradigm shift from traditional practices towards more active and student-centered ones.
\end{abstract}

Keywords: Digital Educational Resources, Educational Technology, Primary School, metalinguistic competence

Palavras-chave: Recursos Educativos Digitais, Tecnologia Digital, 1. ${ }^{\circ}$ Ciclo do Ensino Básico, competência metalinguística

\section{Introdução}

Um recurso educativo digital (RED) pode ser definido, de forma abrangente, como uma "entidade digital desenhada e criada com finalidades educativas" (Ramos et al., 2011, p. 19). São considerados recursos educativos digitais os jogos educativos, os blogues, as páginas web, as apresentações eletrónicas multimédia, entre outros. Tendo por base uma definição de caráter genérico como esta, facilmente se constata que, per se, o uso de RED na escola não se traduz necessariamente em inovação das práticas dos docentes. De facto, as tecnologias digitais são frequentemente usadas como "montra para a atividade expositiva do docente" (Almeida, Delicado, Alves, Carvalho, \& Carvalho, 2015, p. 99) e como suporte para a realização de fichas que pouco diferem das anteriormente realizadas em suporte de papel (Ferrão \& Barbeiro, 2011).

A investigação na área da e-Didática (D’Angelo, 2007) ${ }^{1}$ procura disseminar a ideia de que a introdução das tecnologias digitais na escola deve ser perspetivada como uma oportunidade para alterar as práticas

\footnotetext{
* Investigação financiada pelo programa IDI\&CA do Instituto Politécnico de Lisboa (Projeto COZI_AP, IPL/2019/COZI_AP_ESELx; Projeto RED.PT, IPL/2018/RED.PT_ESELx).
} 
tradicionais vigentes. Em concreto, é defendida a adoção de um modelo construtivista da aprendizagem, em que o aluno assume um papel ativo na gestão do seu processo de aprendizagem, em detrimento de um modo tradicional, transmissivo, que apela à memorização e que perspetiva o aluno como recetáculo da informação transmitida pelo professor. ${ }^{2}$

Assim, com a proliferação de conteúdos e recursos digitais, várias têm sido as vozes que se têm erguido salientando que o desafio que se impõe à educação consiste na seleção/produção de RED "potencialmente inovadores" (Ramos et al., 2011, p. 19). Neste contexto, consideram-se "inovadores" os recursos que "permitam explorar as características únicas da tecnologia promovendo processos de aprendizagem que não podem ser desenvolvidos através dos meios convencionais e sugerem alterações ao contexto educativo, em particular novos objetivos e novos modos de aprendizagem" (Ramos et al., 2011, p. 20).

O presente artigo apresenta dois RED inovadores, desenvolvidos no Instituto Politécnico de Lisboa: Laboratório Gramatical Digital: A Força das Sílabas e Cozinhar a Aprender. O caráter inovador destes recursos resulta de um cruzamento de fatores, entre os quais: (i) a adoção de um modelo construtivista da aprendizagem, centrado em estratégias de descoberta do funcionamento da língua; (ii) a transposição para o contexto digital de metodologias reconhecidas como boas práticas na área da didática da língua portuguesa (laboratório gramatical e percursos didáticos centrados no género textual); (iii) exploração de conteúdos de língua portuguesa a partir de contextos significativos de aprendizagem, recriados através da imersão em cenários virtuais; (iv) a exploração do caráter multimodal das tecnologias digitais, que permite a combinação de texto, imagem (estática e em movimento), som (locução e música) e animação de forma harmoniosa e efetiva, proporcionando a estimulação da aprendizagem através da utilização de canais duplos de processamento.

Após uma breve contextualização do projeto em que se enquadra o desenvolvimento destes recursos (cf. secção 2) e da metodologia seguida para a sua consecução (cf. secção 3), são apresentados os dois RED acima mencionados: Laboratório Gramatical Digital: A Força das Sílabas e Cozinhar a Aprender (cf. secção 4).

\section{Contextualização}

Os RED apresentados neste artigo encontram-se em desenvolvimento no âmbito do projeto RED.PTRecursos Educativos Digitais para o Ensino e Aprendizagem do Português no $1 .{ }^{\circ}$ Ciclo do Ensino Básico, que tem como objetivo geral promover práticas inovadoras no ensino do Português com recurso a tecnologias digitais. Mais especificamente, este projeto visa: (1) criar RED para o ensino e a aprendizagem do Português no $1 .{ }^{\circ}$ Ciclo do Ensino Básico; (2) disponibilizar os RED criados numa plataforma online de acesso livre, alojada na página institucional da Escola Superior de Educação do Instituto Politécnico de Lisboa (IPL); (3) desenvolver investigação sobre a conceção, desenvolvimento e implementação de recursos educativos digitais no $1 .^{\circ}$ Ciclo do Ensino Básico (CEB). ${ }^{3}$

O projeto agrega uma equipa multidisciplinar constituída por docentes do ensino superior politécnico das áreas de Didática do Português, Linguística, Psicolinguística, Desenho e Produção Multimédia, docentes de $1 .^{\circ}$ Ciclo do Ensino Básico em formação na Escola Superior de Educação do Instituto Politécnico de Lisboa (IPL) e formandos da Escola Superior de Comunicação Social do IPL.

\footnotetext{
${ }^{1}$ D’Angelo (2007) propõe o paradigma da e-Didática no contexto do e-learning. Como refere Tchoshanov (2013), "The character "e" in eDidactics means more than just "electronic". Expanding the new acronym, we consider "e" in e-Didactics within the framework of engineering design and 5e model (Bybee et al., 2006), which describes a social constructivist learning cycle, helping students to build new understandings and develop ideas from prior experiences through the following five stages: engagement, exploration, explanation, extension, and evaluation" (p. 9).

${ }^{2}$ No enquadramento curricular atual, esta "mudança de ótica curricular" é sublinhada em diversos documentos oficiais (cf. Roldão, Peralta, \& Martins, 2017, p. 8, para um enquadramento geral do tema).

${ }^{3} \mathrm{O}$ website do projeto encontra-se disponível em $<$ https://www.eselx.ipl.pt/investigacao/recursos/redpt $>$.
} 
Os RED desenvolvidos emergem no contexto da formação desenvolvida no Mestrado de Didática da Língua Portuguesa no $1 .^{\circ}$ e no 2. ${ }^{\circ} \mathrm{CEB}$, em funcionamento na Escola Superior de Educação do IPL. Este é um contexto privilegiado que permite: (i) a seleção de temáticas que emergem das necessidades identificadas pelos docentes de $1 .^{\circ}$ Ciclo em contexto de sala de aula; (ii) a integração dos RED em estudos empíricos que envolvem a conceção, o desenvolvimento, a produção, a implementação (em contexto de sala de aula) e a avaliação dos recursos; (iii) a integração das áreas de didática do português e produção multimédia durante a elaboração dos recursos, a partir do trabalho articulado desenvolvido entre a UC Recursos Multimédia para o Ensino e Aprendizagem e outras UC do plano de estudos (Didática do Português, Estratégias para a Promoção da Atividade Metalinguística e Gestão de Contextos Plurilingues) (Cardoso \& Rodrigues, 2018; Cardoso et al., 2019).

\section{Metodologia}

Para o design instrucional dos recursos, adota-se o modelo ADDIE, que contempla cinco fases: (1) Análise; (2) Desenho; (3) Desenvolvimento; (4) Implementação e (5) Avaliação (ADDIE) (cf. Branch, 2009), assim como um conjunto de procedimentos e práticas associados ao desenvolvimento ágil de software multimédia. A adoção de um modelo evolutivo e incremental permite acelerar o desenvolvimento do projeto, assegurando uma melhoria contínua do processo e promovendo respostas rápidas às mudanças (Stellman \& Greene, 2015) e a adoção de metodologias associadas à produção de projetos multimédia.

$\mathrm{O}$ design multimédia dos RED foi concetualizado a partir de um guião multimédia que, de forma estruturada, planifica os diferentes conteúdos de texto, áudio (narração, ambientes e efeitos), elementos visuais (texto escrito, imagens fixas e em movimento) para apresentar uma narrativa digital interativa (os conteúdos).

Do ponto de vista da produção, os dois RED foram desenvolvidos a partir da programação original, recorrendo às linguagens de programação web HTML, CSS e Javascript.

Os testes de implementação realizados com alunos do $1 .^{\circ} \mathrm{CEB}$, que até ao momento se aplicaram apenas ao recurso Laboratório Gramatical Digital: A Força das Sílabas, recorreram à gravação vídeo, quer dos utilizadores, quer dos ecrãs. Para mais detalhes sobre a implementação destes testes, ver secção 4.1.5.

\section{Resultados}

\subsection{Laboratório Gramatical Digital: A Força das Sílabas}

\subsubsection{Autoria e público-alvo}

Este recurso educativo digital destina-se a alunos de $1 .^{\circ}$ Ciclo do Ensino Básico, do $2 .^{\circ}$ e do $3 .^{o}$ ano. ${ }^{4}$ Foi desenvolvido por uma equipa multidisciplinar constituída por: Liliana Freitas (ideia original e conceção de conteúdos do percurso didático); Adriana Cardoso (conceção de conteúdos do percurso didático e coordenação do projeto); Ricardo Pereira Rodrigues (design multimédia); Edite Fernandes (animação e programação); Dina Caetano Alves (conceção de conteúdos do percurso didático).

\subsubsection{Objetivo e problemática}

O recurso visa promover o desenvolvimento de competências metafonológicas dos alunos em torno do acento fonológico em Português Europeu.

A seleção deste tema prende-se com o facto de uma das investigadoras do projeto, que é docente do $1 .^{\circ}$ $\mathrm{CEB}$, ter constatado que, numa turma de $3 .^{\circ}$ ano de que era titular, persistiam dificuldades na identificação da

\footnotetext{
${ }^{4}$ O protótipo do recurso Laboratório Gramatical Digital: A Força das Sílabas encontra-se disponível em <https://craftsman.pt/redpt/ega/>.
} 
sílaba tónica das palavras, mesmo depois de ter explorado este conteúdo com os alunos, com recurso ao manual escolar e ao truque de "chamar" pela palavra, prolongando a sílaba tónica (cf. Freitas, 2019).

As dificuldades de perceção do acento fonológico em português podem, segundo Araújo (2004), resultar de um problema de instrução ou de fatores linguísticos, nomeadamente da relação entre o acento e a qualidade vocálica. Dado que o estudo de Araújo (2004) tem como amostra alunos de $3{ }^{\circ}$ Ciclo e Ensino Secundário, será interessante o desenvolvimento futuro de estudos que possam investigar a percepção de acento fonológico em alunos do $1 .{ }^{\circ}$ Ciclo do Ensino Básico. De facto, o contraste de desempenho dos alunos de $1 .{ }^{\circ}$ Ciclo que emerge dos relatos de prática dos docentes deste nível de ensino parece sugerir que o trabalho desenvolvido no préescolar ao nível do desenvolvimento da consciência fonológica dos alunos é determinante para explicar o contraste observado.

Quanto ao enquadramento curricular deste tema, em Buescu et al. (2015), os objetivos relativos ao acento da palavra são contemplados no $3 .^{\circ}$ ano do $1 .^{\circ}$ Ciclo. Neste contexto, o objetivo "Explicitar aspetos fundamentais da fonologia do português" é especificado com os descritores: "Classificar palavras quanto ao número de sílabas"; "Distinguir sílaba tónica da átona"; "Classificar palavras quanto à posição da sílaba tónica" (Buescu et al., 2015, p. 57). Já no documento Aprendizagens Essenciais para o $1 .{ }^{\circ}$ Ciclo, os objetivos relativos ao plano fonológico surgem no $2 .^{\circ}$ ano, sendo o principal objetivo "Identificar e distinguir sílaba tónica de átona" (DGE, 2018, p. 22). No 3 . $^{\circ}$ ano, os alunos têm que "Distinguir sílaba tónica de átona e acento prosódico de acento gráfico" (DGE, 2018, p. 12).

\subsubsection{Percurso didático}

Do ponto de vista do percurso didático, o recurso desenvolvido propõe a realização de um laboratório gramatical digital, numa tentativa de articular o ensino da gramática pela descoberta (Duarte, 1992, 2008; Silvano \& Rodrigues, 2010; Xavier, 2012) com o uso de tecnologias digitais na aula de língua (Tavares \& Barbeiro, 2011). Trata-se, pois, de um recurso exploratório, na medida em que se pretende avaliar as possibilidades de transposição da metodologia de laboratório gramatical para um suporte digital.

O percurso didático proposto contempla as seguintes etapas: Questionário Inicial, Experiência 1, Experiência 2 e Questionário Final (cf. Figura 1).

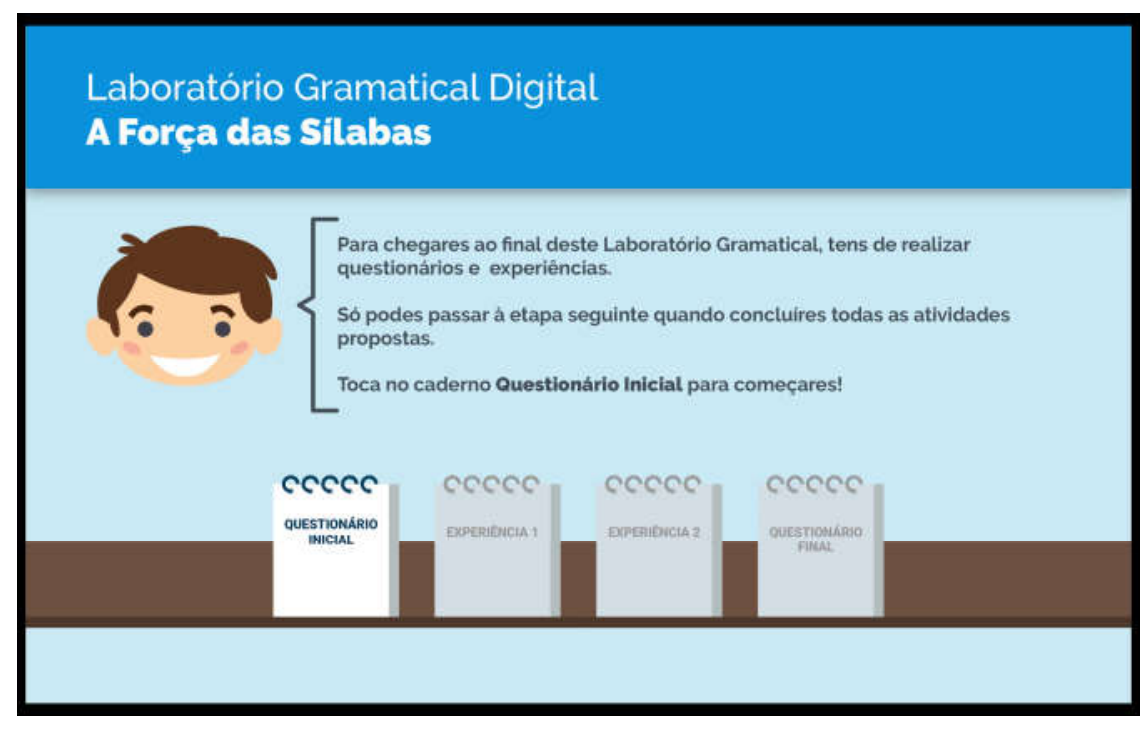

Figura 1: Itinerário do Laboratório Gramatical Digital: A Força das Sílabas 
O Questionário Inicial tem como objetivo aferir as competências metafonológicas dos alunos ao nível da identificação da sílaba forte ${ }^{5}$ das palavras antes da realização do percurso didático. As palavras utilizadas são as que integram a prova de acento do teste ConFIRA - Consciência Fonológica: Instrumento de Rastreio e Avaliação (Castro, Alves, Correia, \& Soares, em prep.), a saber: morada, óculos, lápis, capa, rainha, chaminé e aspirador. Estas palavras não são representadas graficamente no recurso, sendo disponibilizadas apenas as imagens e os áudios com a pronúncia das palavras.

Seguindo os procedimentos descritos em Alves (2014), no recurso apresenta-se a segmentação em sílabas das palavras através de círculos. O utilizador deve selecionar a sílaba forte tocando no círculo respetivo, que fica preenchido com sombreado cinzento (cf. Figura 2).

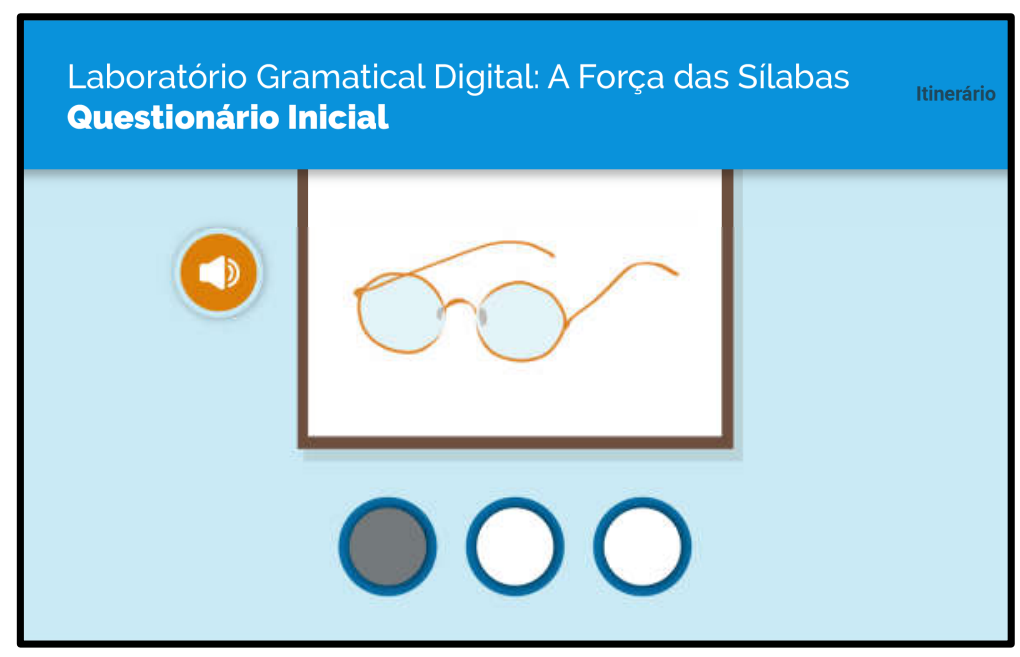

Figura 2: Exemplo de ecrã do Questionário Inicial, palavra óculos, Laboratório Gramatical Digital: A Força das Sílabas

A Experiência 1 tem como objetivo promover a identificação da sílaba tónica das palavras recorrendo à estratégia de "prolongar" (i.e. dizer mais lentamente) a sílaba forte. ${ }^{6}$ É composta por duas tarefas distintas: (i) uma tarefa centrada na perceção da sílaba forte de palavras a partir da audição de partes selecionadas de uma canção; (ii) uma tarefa centrada na produção, em que os alunos gravam partes de uma canção. Para o efeito, é proposta a visualização do videoclipe da canção "O pica do sete" de António Zambujo, orientada para a exploração das palavras em final de verso em que existe coincidência entre acentuação musical (sons fortes e leves) e acentuação fonológica das palavras (sílaba forte e sílaba fraca). As palavras que são exploradas neste contexto são: cedinho, ninho, paragem, bandolete, sete, viagem, queria, dia, passar, cético, elétrico e sonhar. A partir da análise da forma como são produzidas as três primeiras palavras, os alunos são levados a concluir que a sílaba forte das palavras é dita mais lentamente do que as sílabas fracas (cf. Figuras 3-5).

\footnotetext{
${ }^{5}$ De forma a não introduzir metalinguagem no recurso educativo digital, optou-se por usar as designações sílaba forte e sílaba fraca em vez de sílaba tónica e sílaba átona.

${ }^{6}$ Um revisor do texto questiona se um utilizador que tenha acertado em todos os itens do Questionário Inicial prossegue no recurso, passando por todas as experiências propostas. No seu formato atual, é isso que acontece. No futuro, será importante desenvolver um backoffice que permita que o professor monitorize o progresso dos alunos no recurso, podendo encaminhá-los para percursos diferenciados em função do seu desempenho. Ou seja, neste caso concreto, o docente poderia aceder ao resultado dos alunos no Questionário Inicial e, a partir daí, indicar os alunos que deveriam continuar a desenvolver as Experiências propostas no recurso.
} 


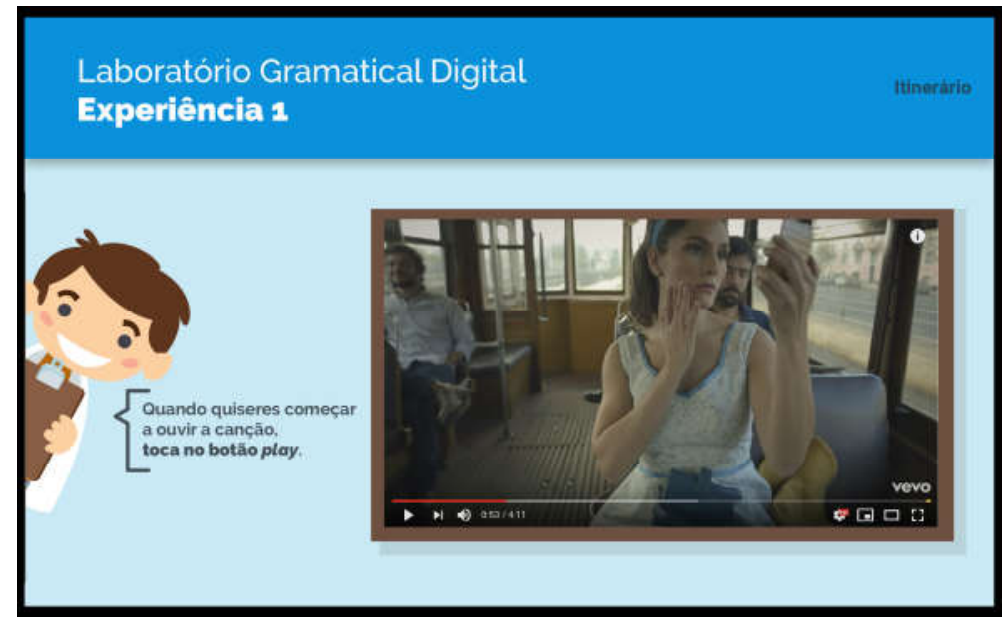

Figura 3: Ecrã do Exercício 1, videoclipe, Laboratório Gramatical Digital: A Força das Sílabas

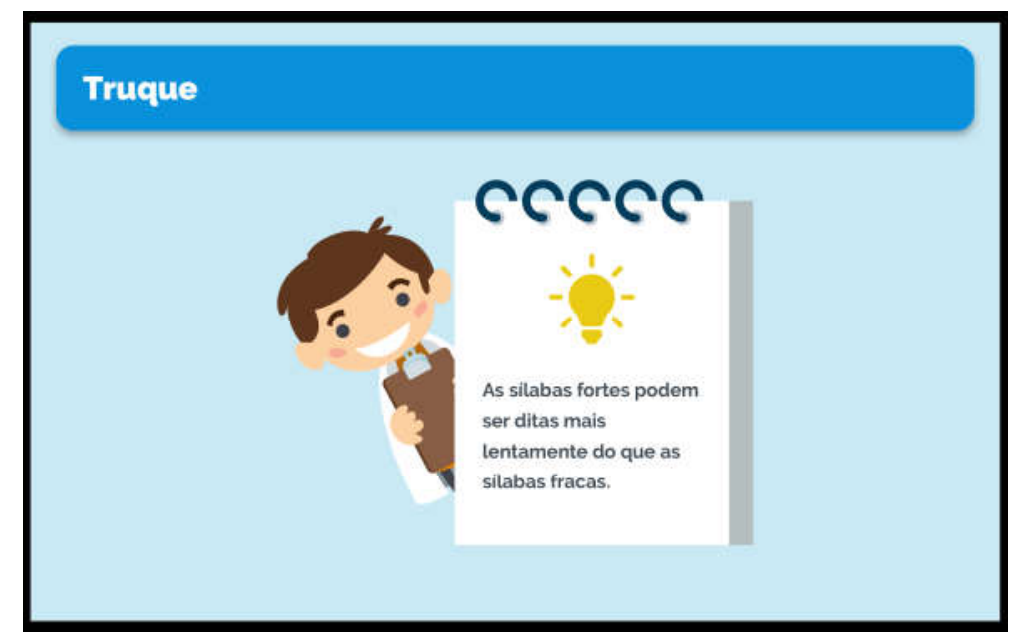

Figura 4: Ecrã do Exercício 1, Sistematização, Laboratório Gramatical Digital: A Força das Sílabas

Na segunda tarefa da Experiência 1, o utilizador mobiliza a estratégia apresentada anteriormente. Seguindo o exemplo do cantor António Zambujo, o utilizador deve cantar alguns versos da música "Pica do 7", dizendo mais lentamente a sílaba forte da última palavra de cada verso. A sua produção fica gravada, de forma a que possa comparar a sua gravação com a versão de António Zambujo (cf. Figura 5). Caso considere que a sua versão não está parecida com a do cantor, pode repetir a gravação. De seguida, o utilizador identifica a sílaba forte da última palavra de cada verso, recorrendo à estratégia sugerida. 


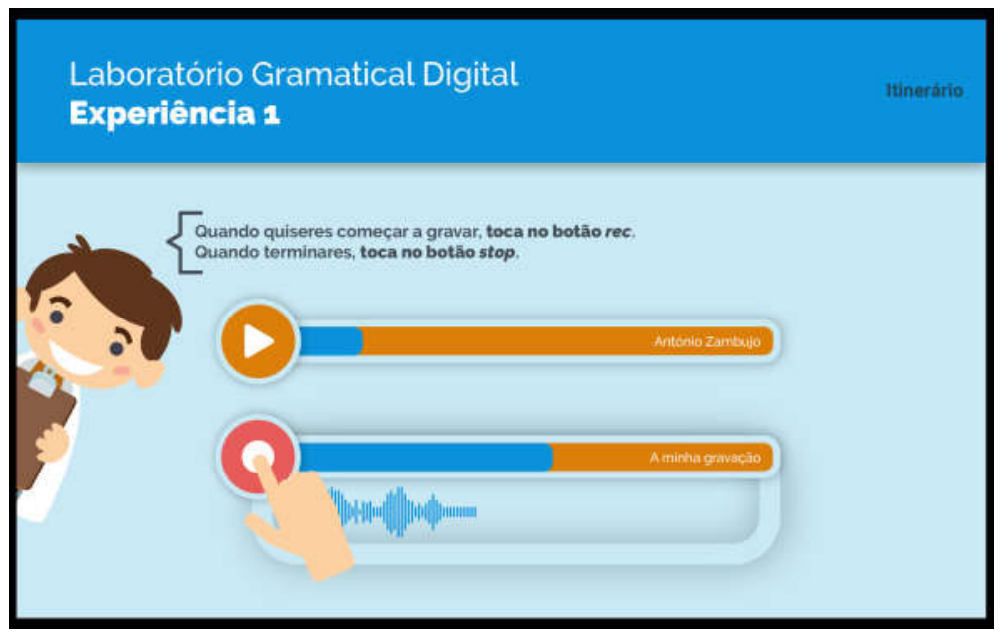

Figura 5: Experiência 1, Tarefa 2- Gravação de voz

$\mathrm{Na}$ Experiência 2, o utilizador ouve a mesma palavra dita de duas formas diferentes: (i) com prolongamento da sílaba forte; (ii) com prolongamento de uma das sílabas fracas. Após a audição de ambas as opções, o utilizador clica no botão correspondente à opção em que a palavra é produzida com prolongamento da sílaba forte. As palavras analisadas são pulmão, pato, estudar, calças, tambor, gorila e jornais. Tal como no Questionário Inicial, estas palavras não ocorrem representadas graficamente, sendo apenas apresentadas as imagens e os áudios correspondentes.

Por fim, o Questionário Final tem como objetivo comparar os resultados obtidos antes e depois da realização do percurso didático proposto no RED. Sendo o Questionário Final constituído pelos mesmos itens que o Questionário Inicial, espera-se poder avaliar se a realização do percurso teve impacto nas aprendizagens dos alunos. ${ }^{7}$

\subsubsection{Interatividade}

No recurso Laboratório Gramatical Digital: A Força das Sílabas, os utilizadores recebem feedback corretivo automático na maioria dos itens. Tal não acontece apenas em duas atividades: (i) Questionário Inicial e (ii) atividade de gravação de voz (cf. Figura 5). Dado que o questionário aplicado no início do RED é novamente aplicado no final do recurso, não é apresentado feedback automático corretivo no Questionário Inicial. Só no final do recurso são indicados os itens em que o utilizador acertou no Questionário Inicial e Questionário Final. Na atividade de gravação de voz, também não é dado feedback corretivo, dado que o que se pretende é que seja o próprio utilizador a monitorizar a sua aprendizagem, comparando a sua produção com a do cantor António Zambujo.

Ao longo do RED, é implementada uma estratégia de gamificação através da atribuição de estrelas em função do número de itens a que o utilizador responde corretamente. Nas atividades de gravação de voz e nos questionários, é atribuída apenas uma estrela pela realização da atividade, independentemente do desempenho do utilizador.

\footnotetext{
${ }^{7}$ Tal como sugerido por um dos revisores do texto, em futuras versões deste RED poderá ser equacionada a hipótese de acrescentar outras palavras ao Questionário Final (não previstas no Questionário Inicial) de forma verificar se há transferência da competência para novos itens.
} 


\subsubsection{Implementação}

Para a avaliação e testes com utilizadores, adotaram-se as heurísticas propostas por Nielsen (1994), adaptadas especificamente à usabilidade de crianças (Alsumait \& Al-Osaimi, 2010). A aplicação da análise heurística permitiu confrontar a conceção do RED desenvolvida pela equipa de investigação com a utilização efetiva do RED por parte do público-alvo.

No total, foram testados 22 alunos do $1 .^{\circ} \mathrm{CEB}$. Os resultados destes testes forneceram um conjunto de dados que permitiu corrigir algumas das propostas iniciais, assim como identificar alguns erros de programação, que foram corrigidos (cf. Freitas, 2019).

\subsection{Cozinhar a Aprender}

\subsubsection{Autoria e público-alvo}

Este recurso educativo digital destina-se a alunos do $3 .^{\circ}$ ano do $1 .{ }^{\circ}$ Ciclo do Ensino Básico ${ }^{8}$. Encontra-se a ser desenvolvido por uma equipa multidisciplinar constituída por: Adriana Cardoso (conceção de conteúdos do percurso didático e coordenação do projeto); António Almeida, Carolina Gonçalves, Susana Pereira, Margarida Rodrigues, Encarnação Silva e Bruno Paulos (conceção do percurso didático); Ricardo Pereira Rodrigues e Joana Souza (design multimédia); Joana Souza (ilustração); Nuno Palma (animação e programação). São ainda consultadores deste projeto: Ana Raquel Simões; Dulce Sarroeira; Beatriz Garcia Fernández e Dina Caetano Alves.

As atividades propostas no recurso desenvolvem-se a partir da exploração do género textual receita culinária. Apesar de este género textual não ser explicitamente referido no Programa e Metas Curriculares de Português para o Ensino Básico (Buesco et al., 2015), nas Aprendizagens Essenciais (DGE, 2018), relativas ao $3 .^{\circ}$ ano de escolaridade, refere-se, no Domínio da Escrita, "Escrever textos de géneros variados, adequados a diferentes finalidades como narrar e informar, em diferentes suportes" (cf. DGE, 2018, p. 11) e no Domínio da Leitura: "Ler textos com características descritivas e narrativas" (cf. DGE, 2018, p. 8). Como referem Cardoso et al. (2009), "considerando que a receita tem uma estrutura compositiva em que predominam as sequências descritivas, o ensino da receita culinária estará justificado” (p. 198).

Por outro lado, como referem Cardoso et al. (2009), a exploração de receitas culinárias é pertinente, quer do ponto de vista da promoção da integração curricular, quer do ponto de vista do desenvolvimento de competências em Português. Do ponto de vista da integração curricular, podem ser trabalhados, na área do Estudo do Meio, tópicos como a saúde alimentar, a origem dos ingredientes em termos biogeográficos e a escolha de ingredientes tendo em conta a sustentabilidade do planeta. Na área da Matemática, a receita permite trabalhar situações problemáticas relacionadas com os números racionais e as medidas de massa e de capacidade, bem como conceitos como a proporcionalidade e problemas envolvendo operações e dinheiro (Cardoso et al., 2019, p. 198). ${ }^{9}$

No que diz respeito à área de Português, "a receita possibilita, no domínio da compreensão de leitura, aprender a mobilizar estratégias de localização da informação, compreendendo previamente que a disposição no layout da página, o recurso a subtítulos, a variação de tipos, tamanhos e cores de letras funcionam como organizadores textuais e facilitam a localização da informação na unidade que é uma receita" (Cardoso et al., 2019, p. 198). No domínio da gramática, a receita culinária é um contexto facilitador da exploração de diversos

\footnotetext{
${ }^{8}$ O protótipo do recurso Cozinhar a Aprender encontra-se disponível em $<\underline{\text { https: } / / \text { redpt.pt } />}$

${ }^{9}$ Outras áreas poderiam estar envolvidas nesta articulação, mas, dado o carácter exploratório do recurso Cozinhar a Aprender, opta-se por considerar apenas a articulação entre as áreas de Português, Matemática e Estudo do Meio. No futuro, será pertinente implementar a integração de outras áreas no desenvolvimento de recursos educativos digitais.
} 
conteúdos, como os campos lexicais, as classes de palavras (como o quantificador numeral) e a flexão verbal (Cardoso et al, 2019, p. 199).

\subsubsection{Objetivo e problemática}

O recurso Cozinhar a Aprender visa promover o desenvolvimento integrado de competências (português, matemática, estudo do meio) a partir da exploração do género textual receita culinária. A ideia subjacente ao desenvolvimento deste recurso é a de, por um lado, mobilizar o potencial das tecnologias digitais para a promoção da integração curricular (cf. secção 4.2.1.). Por outro lado, pretende-se testar a transposição didática para suporte digital de uma metodologia reconhecida como boa prática no ensino de língua, que consiste na implementação de práticas de leitura e escrita centradas em géneros textuais. Como referem Cardoso et al. (2009, p. 196), seguem-se, neste contexto, as orientações do designado grupo de Genebra, que preconiza que “o ensino da escrita seja feito através da didatização dos géneros textuais, privilegiando a dimensão social da escrita e uma perspetiva discursiva que procura reproduzir no ensino, dentro do possível, o contexto real de produção e circulação do género na sociedade (Bronckart, 1996, 2008; Dolz e Gagnon, 2010; Dolz, Noverraz e Schneuwly, 2001). O ensino dos géneros textuais tem, pois, subjacente uma valorização do contexto em que circula o género e uma valorização da dimensão social da escrita." (p. 196).

\subsubsection{Percurso didático}

O recurso Cozinhar a Aprender proporciona uma contextualização do género textual receita de culinária através da recriação de um ambiente fictício que permite a imersão sensorial (visão e audição) num espaço de restauração.

As atividades propostas no recurso organizam-se em torno de três módulos: (i) contextualização; (ii) exploração da receita culinária; (iii) produção escrita (cf. Figura 6).

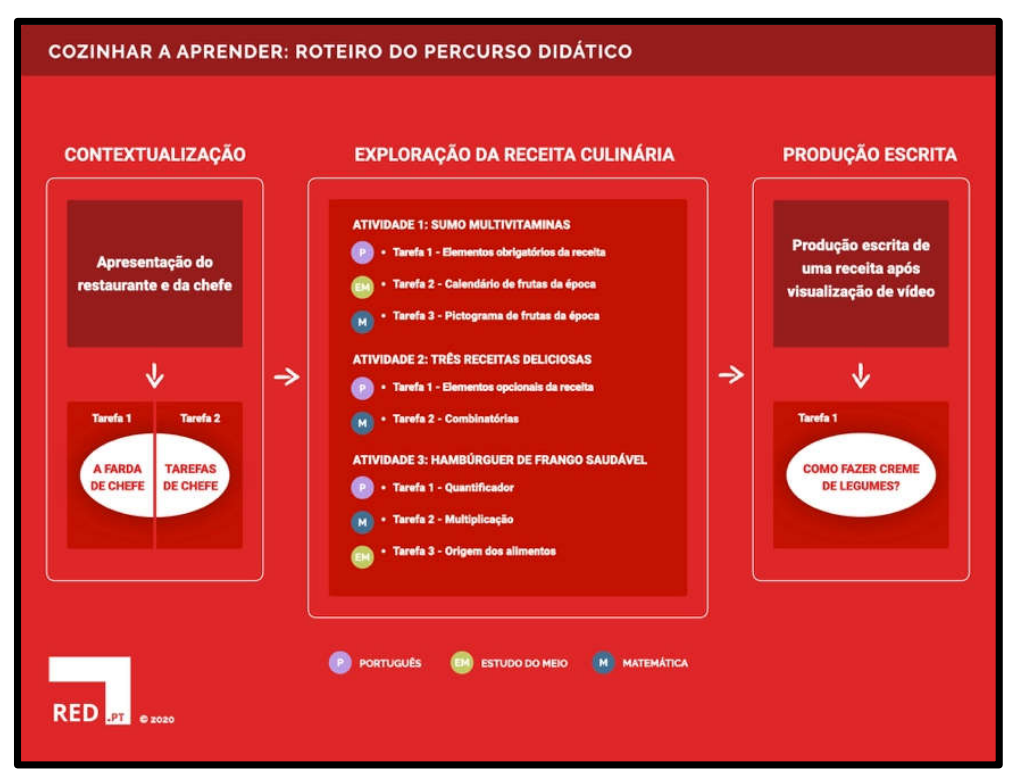

Figura 6: Roteiro do recurso Cozinhar a Aprender 
No módulo de contextualização, o utilizador entra no restaurante Sabores Mágicos (cf. Figura 7) e é recebido pela chefe Raquel Veloso (cf. Figura 8). De forma a criar uma maior empatia e entendimento do cenário em que decorre toda a experiência, o utilizador é orientado para atividades sobre a farda de chefe de cozinha (cf. Figura 9) e sobre as tarefas de um chefe.

No módulo principal do recurso, em que são apresentadas atividades de exploração da receita culinária, são disponibilizadas três atividades que promovem a articulação curricular (português, estudo do meio e matemática).

Ao nível do português, são explorados: os elementos obrigatórios e opcionais da receita culinária (atividades 1 e 2, cf. Figura 10); os quantificadores (atividade 3, cf. Figura 11).

Por fim, no último módulo, o utilizador é desafiado a produzir uma receita escrita a partir de um registo audiovisual, o que permitirá a mobilização dos conhecimentos adquiridos ao longo do recurso (cf. Figura 12).

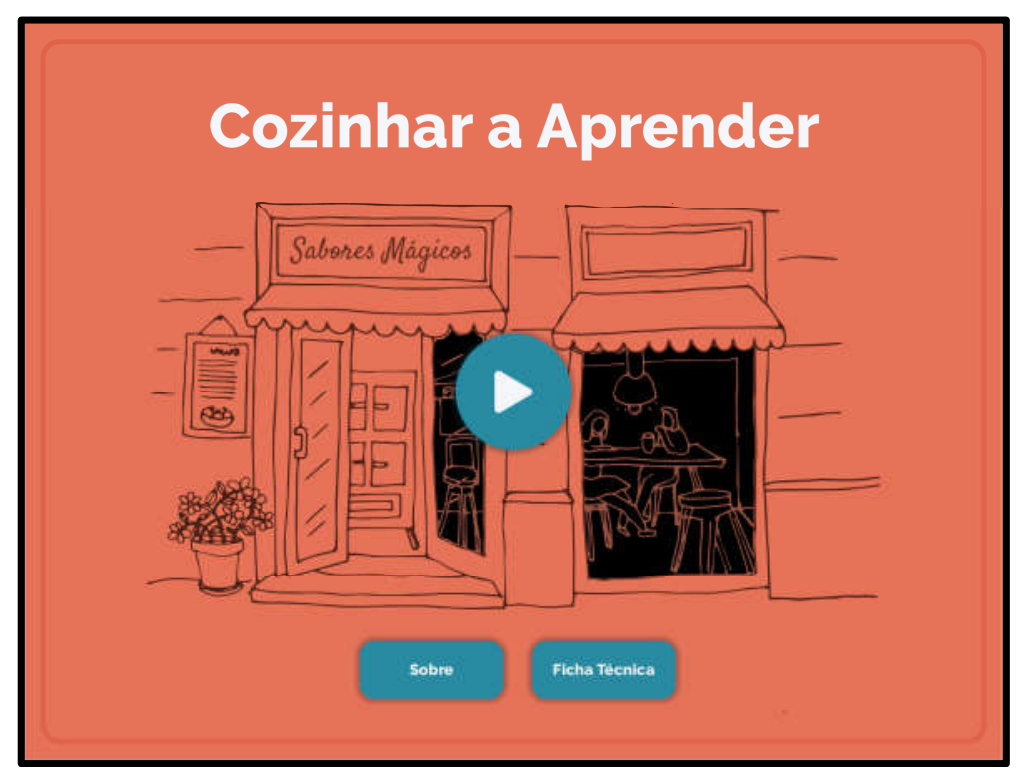

Figura 7: Ecrã 1, Recurso Cozinhar a Aprender 


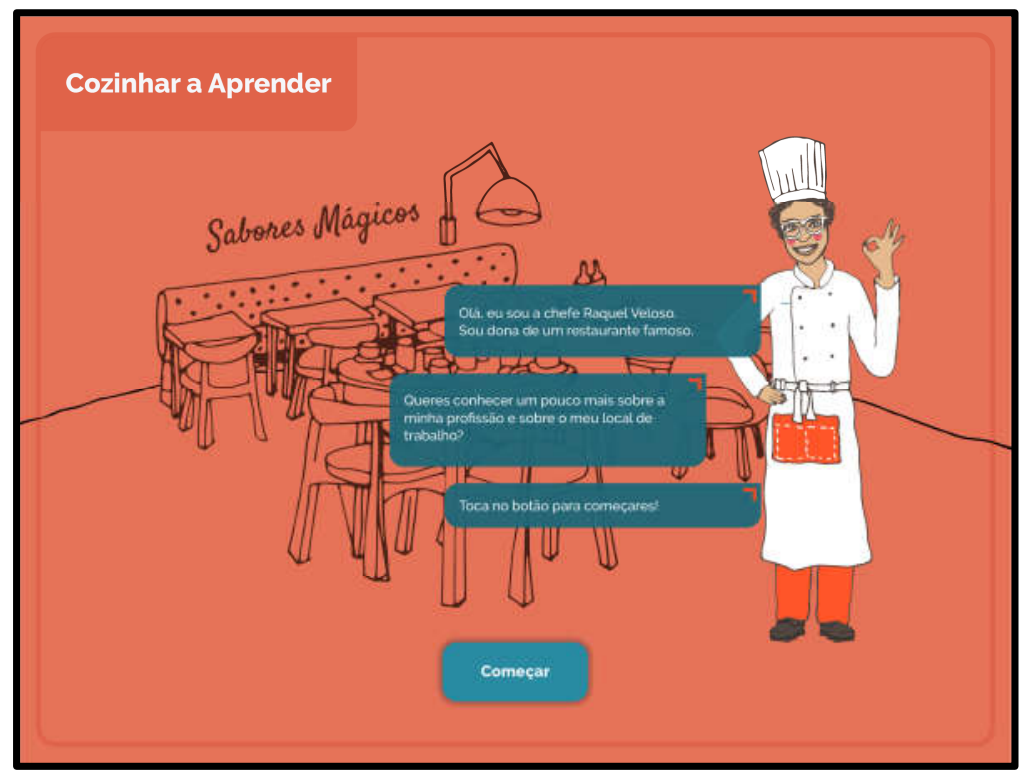

Figura 8: Ecrã 2, Recurso Cozinhar a Aprender

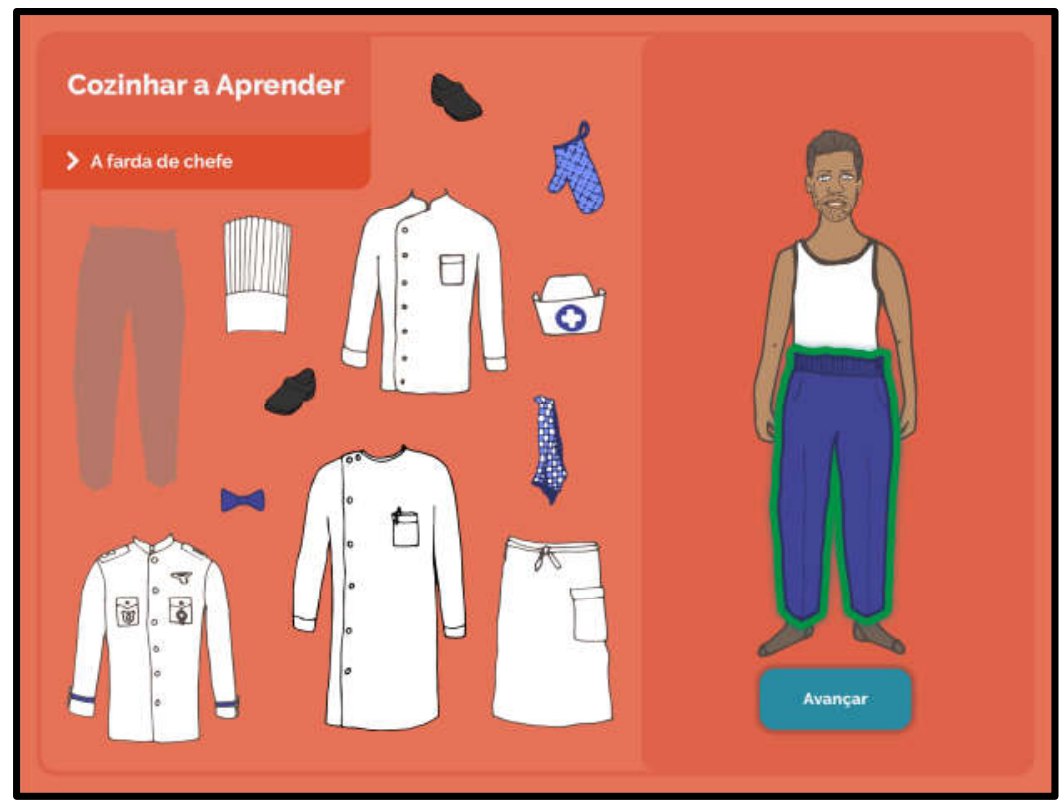

Figura 9: Atividade Farda de chefe, Recurso Cozinhar a Aprender 
Adriana Cardoso, Ricardo Pereira Rodrigues, Liliana Freitas e Dina Caetano Alves

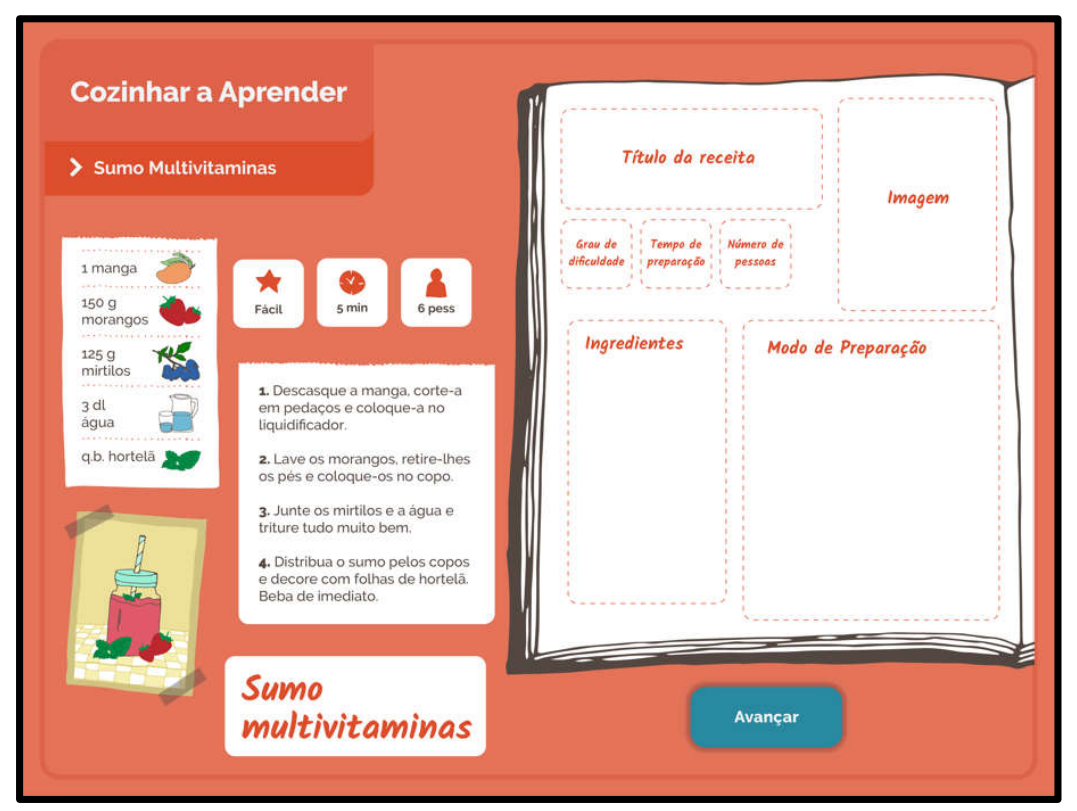

Figura 10: Atividade Sumo Multivitaminas, Recurso Cozinhar a Aprender

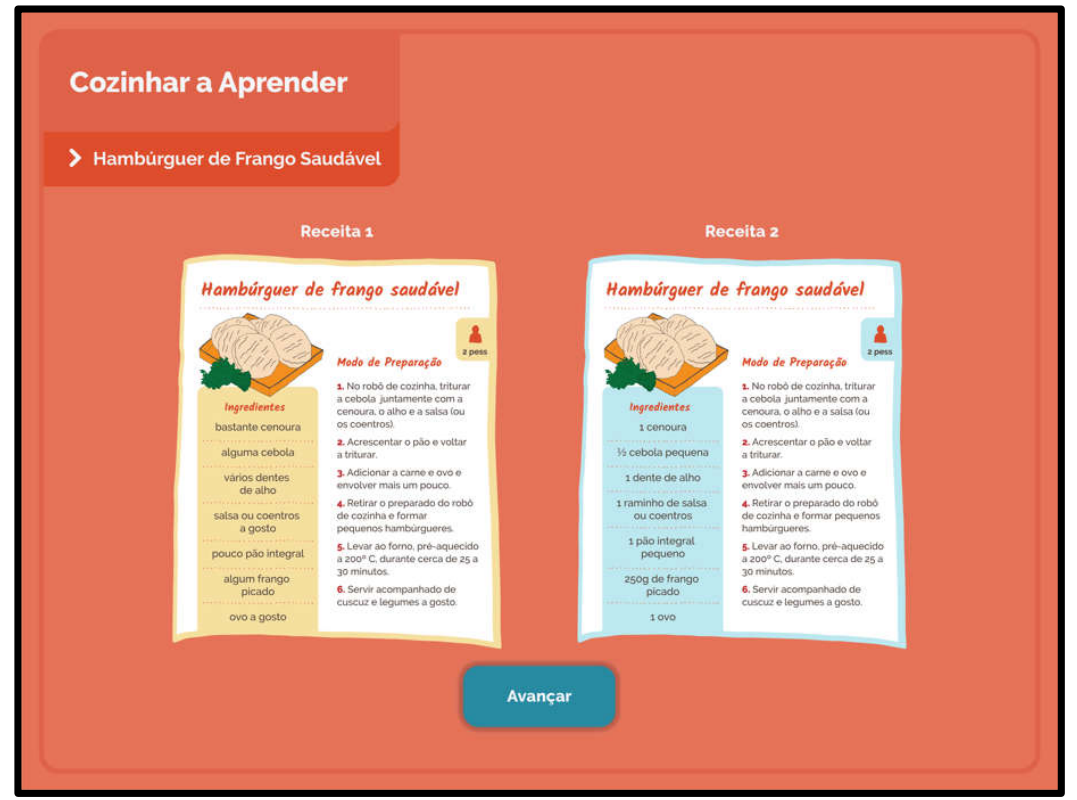

Figura 11: Atividade Hambúrguer de Frango Saudável, Recurso Cozinhar a Aprender 


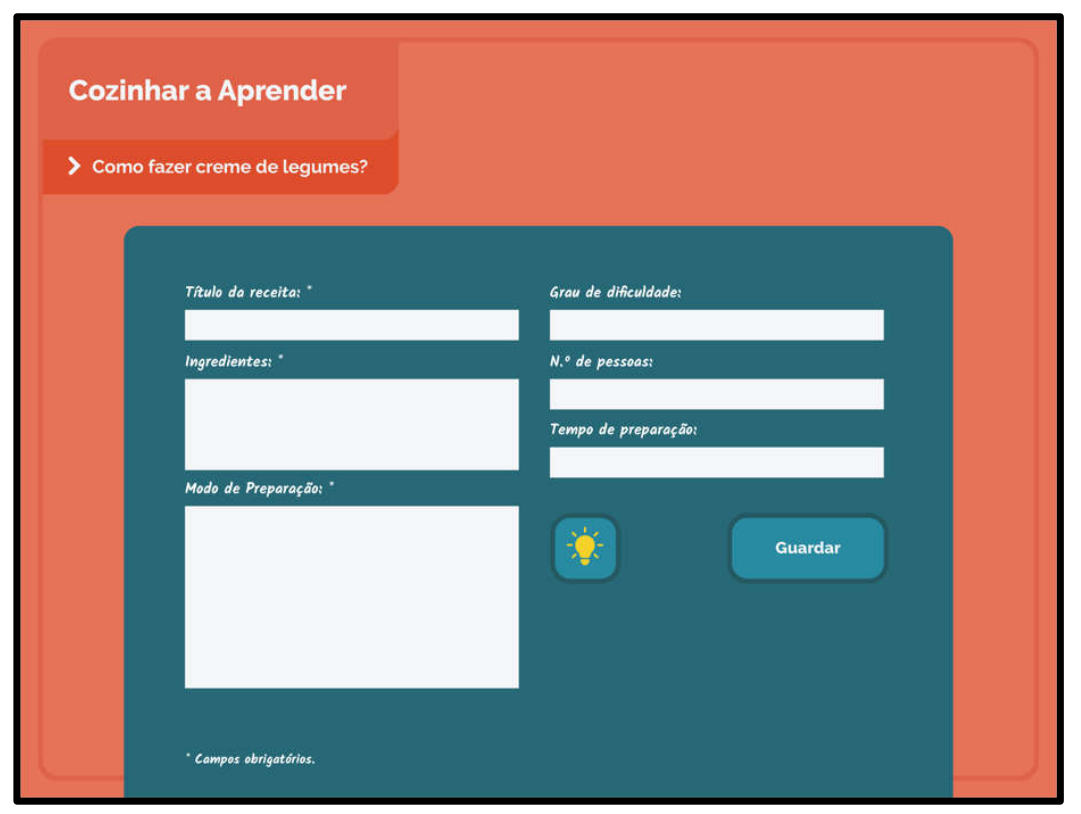

Figura 12: Atividade Como fazer creme de legumes?, Recurso Cozinhar a Aprender

\subsubsection{Interatividade}

No recurso Cozinhar a Aprender, os utilizadores recebem feedback corretivo automático em todos os itens, exceto na produção escrita final. Neste caso, após visionamento de um vídeo (Como fazer creme de legumes?), os utilizadores preenchem um formulário com os diferentes elementos que integram o plano da receita e é gerado um layout que integra a receita culinária produzida.

A estratégia de gamificação implementada consiste na atribuição de miniestrelas em função da superação das atividades propostas. Como se ilustra na Figura 10, a metáfora utilizada é a de uma slot machine, em que os algarismos vão rodando e as miniestrelas vão aparecendo em função dos pontos alcançados pelo utilizador. 


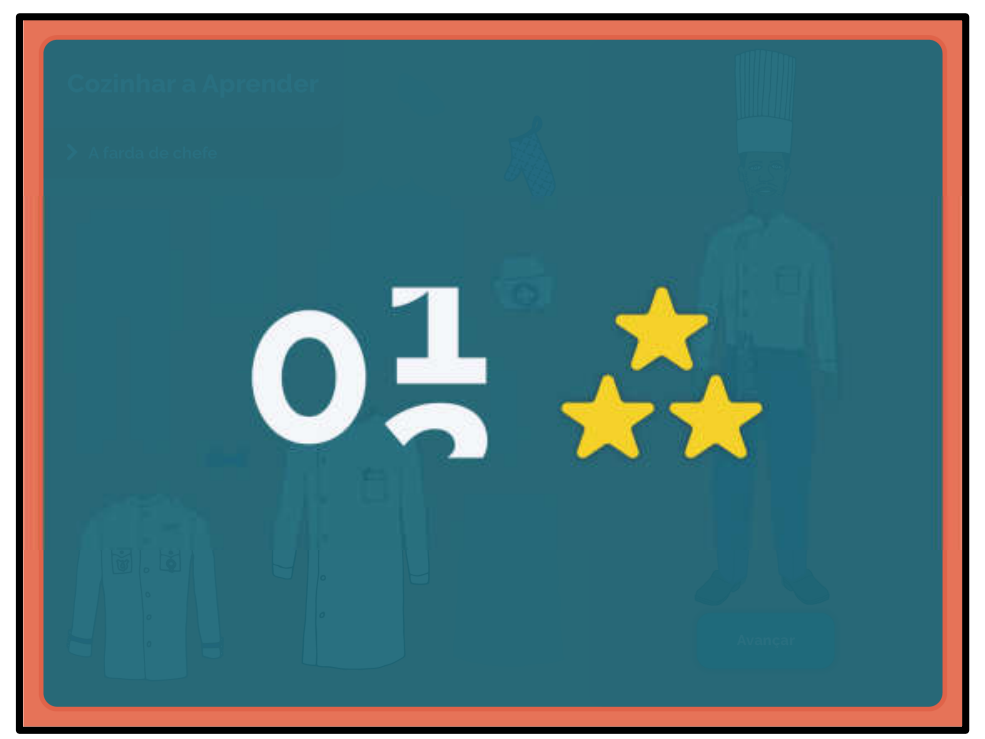

Figura 10: Ecrã de gratificação, Recurso Cozinhar a Aprender

\subsubsection{Implementação}

O recurso Cozinhar a Aprender ainda não foi testado com utilizadores nem foi analisado em termos de heurística de usabilidade. Este processo será desenvolvido no ano letivo de 2020/2021 no âmbito de um projeto de intervenção em curso no Mestrado de Didática da Língua Portuguesa no $1 .^{\circ}$ e no $2 .^{\circ}$ Ciclo do Ensino Básico.

\section{Considerações finais}

Os próximos passos a desenvolver no âmbito do projeto RED.PT envolvem a implementação e avaliação dos RED, tendo em vista a sua testagem junto de uma amostra mais alargada de utilizadores, de forma a avaliar o impacto que os RED têm na aprendizagem dos alunos.

Neste percurso, a equipa de investigação tem definido linhas orientadoras fundamentais para o desenvolvimento futuro de RED em diferentes dimensões (desenho instrucional; aprendizagem multimédia; design multimédia e heurísticas de usabilidade).

A partir deste projeto exploratório, a principal problemática que emerge é a do desenvolvimento sustentável de recursos educativos digitais com características semelhantes, considerando a relação entre a necessidade de recursos educativos digitais de qualidade, o tempo de execução de um recurso e o custo que lhe está associado. Uma resposta adequada do Ministério da Educação a esta problemática terá necessariamente de avaliar estas variáveis e de oferecer uma resposta sustentável a esta equação.

\section{Referências:}

Almeida, Ana Nunes, Ana Delicado, Nuno de Almeida Alves, Tiago Carvalho, \& Diana Carvalho (2015) Infâncias Digitais. Lisboa: Fundação Calouste Gulbenkian.

Alves, Dina Caetano (2014) (Re)habilitação do conhecimento (meta)fonológico - proposta de uma metodologia de intervenção desenvolvida à luz da prática baseada na evidência. Trabalho de natureza profissional para 
atribuição do Título de Especialista na área 7.72.726 - Terapia e Reab. Escola Superior de Saúde do Instituto Politécnico de Setúbal.

Alsumait, Asmaa \& Asma Al-Osaimi (2010) Usability Heuristics Evaluation for Child E-learning Applications. Journal of Software, 5 (6), pp. 654-661.

Araújo, Isabel (2004). A Percepção do Acento em Português: Descrição, Implicações e Aplicações para o Ensino do Português como Língua Materna. (Dissertação de mestrado), Faculdade de Letras da Universidade de Lisboa, Lisboa.

Branch, Robert Maribe (2009) Instructional Design: The ADDIE Approach. Georgia: Springer.

Buescu, Helena C., José Morais, Maria Regina Rocha, \& Violante F. Magalhães (2015) Programa e Metas

Curriculares de Português do Ensino Básico. Ministério da Educação e Ciência.

Castro, Ana, Dina Caetano Alves, Susana Correia, \& Carla Soares (s.d.) Consciência Fonológica - Instrumento de Rastreio e Avaliação (ConF.IRA).

Cardoso, Adriana \& Ricardo Pereira Rodrigues (2018) Recursos educativos digitais para o ensino e a aprendizagem do Português no $1 .^{\circ}$ Ciclo do Ensino Básico. In A. Carneiro-Barrera \& A. Díaz-Román (Orgs.), Avances En Ciencias de La Educación y Del Desarrollo, 2018. Granada: Asociación Española de Psicología Conductual, pp. 722-729.

Cardoso, Adriana, Ricardo Pereira Rodrigues, Bruno Paulos, Carolina Gonçalves, Susana Pereira, \& Encarnação Silva (2019) A receita culinária: Recurso educativo digital para o desenvolvimento de competências textuais e linguísticas no 1. ${ }^{\circ}$ CEB. In Percursos de Interdisciplinaridade em Português: Dos projetos às práticas. Lisboa: Associação de Professores de Português, pp. 193-208.

D’Angelo, Giuseppe (2007) From Didactics to e-Didactics: e-Learning Paradigms, Models and Techniques. Napoli: Liguori.

DGE. (2018) Aprendizagens Essenciais: articulação com o perfil dos alunos 2. ${ }^{\circ}$ ano. Lisboa: Ministério da Educação.

Duarte, Inês (1992) Oficina gramatical: contextos de uso obrigatório do conjuntivo. In Delgado-Martins et alii, Para a Didáctica do Português. Seis estudos de Linguística, Lisboa: Edições Colibri, pp. 165-177.

Duarte, Inês (2008) O conhecimento da língua: Desenvolver a consciência linguística. Lisboa: ME/DGIDC.

Ferrão, Clara \& Luís Filipe Barbeiro (2011) As implicações das TIC no ensino da língua. Lisboa: DirecçãoGeral de Inovação e de Desenvolvimento Curricular.

Freitas, Liliana (2019) Laboratório Gramatical Digital: Desenvolver competências metafonológicas em torno do acento fonológico em Português Europeu. Dissertação de Mestrado. Escola Superior de Educação de Lisboa.

Nielsen, Jakob (1994) Usability inspection methods. In R. L. Mack \& J. Nielsen (Eds.), Usability inspection methods. New York: John Wiley \& Sons, pp. 141-172.

Ramos, José Luís, Vítor Duarte Teodoro \& Francisco Melo Ferreira (2011) Recursos educativos digitais. Reflexões sobre a prática. Cadernos SACAUSEF VII, 11-34.

Roldão, Maria do Céu, Helena Peralta, \& Isabel P. Martins (2017) Currículo do Ensino Básico e Secundário para a construção de aprendizagens essenciais baseadas no perfil dos alunos. Lisboa: Ministério da Educação.

Silvano, Purificação \& Sónia Rodrigues (2010) A Pedagogia dos Discursos e o Laboratório Gramatical no ensino da gramática: Uma proposta de articulação. In A. M. Brito (Ed.), Gramática: História, Teorias, Aplicações. Porto: CLUP, pp. 275-286.

Stellman, Andrew \& Jennifer Greene (2015) Learning Agile: Understanding scrum, XP, lean and Kanban. Sebastopol, CA: O'Reilly.

Tchoshanov, Mourat (2013) Engineering of Learning: Conceptualizing e-Didactics. Moscovo: UNESCO Institute for Information Technologies in Education.

Xavier, Lola Geraldes (2012). Ensinar Gramática pela Abordagem Ativa de Descoberta, Exedra: Revista cientifica, Português: Investigação e Ensino, ESEC, pp. 468-477. 